IMAGES IN MEDICINE

\title{
Selective angiographic catheterisation for jejunal angiodysplasia
}

A 70 year old man was admitted to the high dependency unit after a large rectal bleed of fresh blood. Physical examination revealed a soft abdomen, fresh rectal blood, tachycardia, and hypotension. Haematological investigations disclosed a low haemoglobin concentration. Gastroscopy, colonoscopy, and coeliac

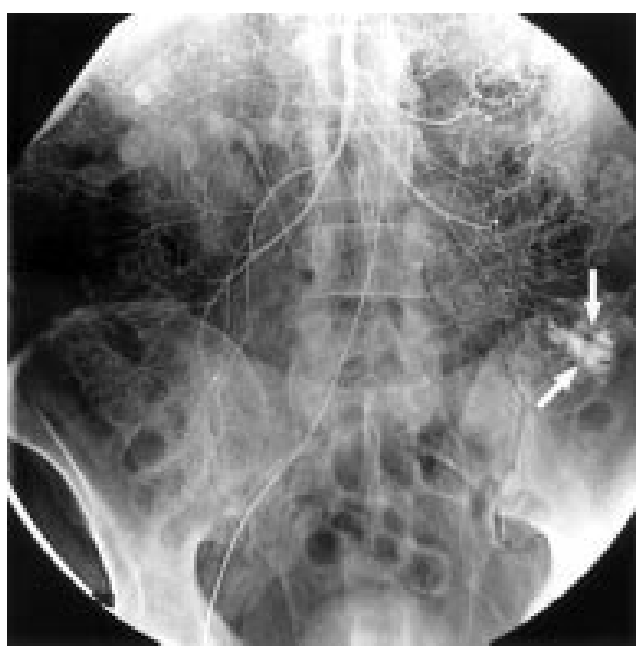

Figure 1 Selective catheterisation of the superior mesenteric artery. showing blood accumulating in the small bowel lumen.

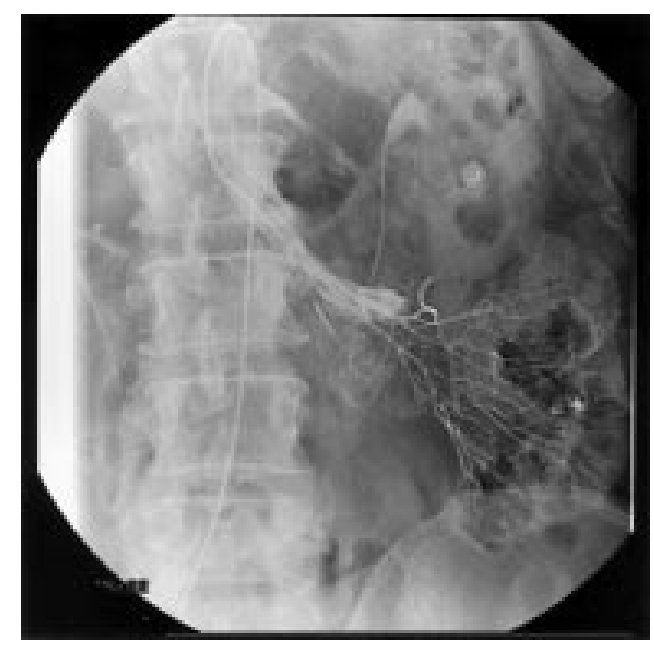

Figure 2 Selective catheterisation of the bleeding jejunal branch.

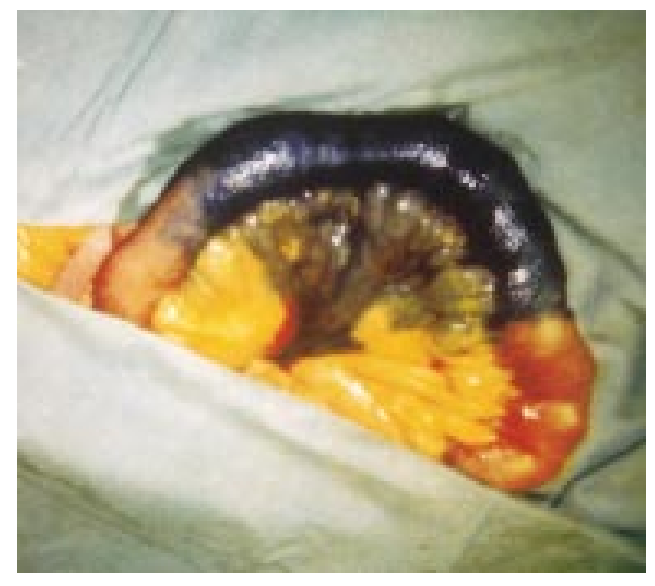

Figure 3 Methylene blue injection showing affected segment of small bowel.

axis angiography performed a week earlier after a three day history of melaena had failed to identify a bleeding point. He was resuscitated and mesenteric angiography via a right superficial femoral artery puncture was performed. Selective catheterisation of the superior mesenteric artery was performed, this showed blood accumulating in the small bowel lumen (see arrows in fig 1). Selective catheterisation of the bleeding jejunal branch for a surgical map was carried out (fig 2). At laparotomy the affected segment of small bowel was easily identified by the methylene blue injection (fig 3), and a small bowel resection was carried out with an end to end anastomosis. Histologically, the specimen showed widespread diverticulosis and angiodysplasia with numerous large thin walled dilated vessels. Postoperatively the patient had an uneventful course and was allowed home on the 11th hospital day. At two month follow up he was well and his haemoglobin had remained stable.

M H ROBINSON $S$ A HUSSAIN

City Hospital, Nottingham, UK Correspondence to: Dr Saj A Hussain, Department of Orthopaedics, King's College Hospital, Denmark Hill, London SE5 9RS, UK 